\title{
Survey of treatment process in water treatment plant and the characteristics of flocs formed by two new coagulants
}

\author{
Hui Xua ${ }^{\mathrm{a}}$, Feng Xiao ${ }^{\mathrm{a}, *}$, Dongsheng Wang ${ }^{\mathrm{a}}$, Changqing Ye ${ }^{\mathrm{b}}$ \\ a State Key Laboratory of Environmental Aquatic Chemistry, Research Center for Eco-Environmental Sciences, Chinese Academy of Sciences, 18, Shuangqing \\ Road, Beijing 100085, China \\ b School of Public Health, Nantong University, Nantong, Jiangsu Province 226019, China
}

\section{H I G H L I G H T S}

- The peak value of residual $\mathrm{Al}$ was at summer.

- PH values may be an important factor.

- COD value and residual Al presented the strictly positive correlation.

- Nano particles can bridge the particles together.
G R A P H I C A L A B S T R A C T

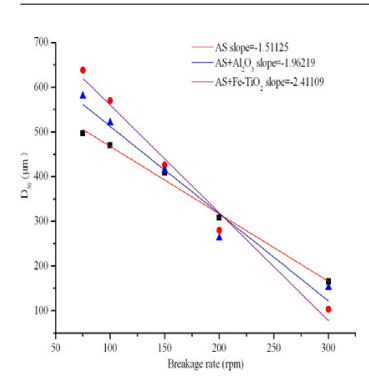

\begin{abstract}
A B S T R A C T
The relationship between $\mathrm{pH}$, turbidity and COD of raw water with the residual $\mathrm{Al}$ in the filtrated water was investigated. The results indicated that the COD in raw water may have the maximum effects on the residual Al. The $\mathrm{pH}$ value of raw water had significant effects with the residual $\mathrm{Al}$, but the relationship was not significant in the latter half of the year. The characteristics of water in the Yellow River had no significant relationship with the quality of filtrated water. In order to get better coagulation performances, two new coagulants $\left(\mathrm{AS}\left(\mathrm{Al}_{2}\left(\mathrm{SO}_{4}\right)_{3}\right)+\mathrm{Fe}-\mathrm{TiO}_{2}\right.$ and $\left.\mathrm{AS}\left(\mathrm{Al}_{2}\left(\mathrm{SO}_{4}\right)_{3}\right)+\mathrm{Al}_{2} \mathrm{O}_{3}\right)$ were applied to treat the raw water, and the characteristics of flocs were investigated. The results indicated that when nano particles $\left(\mathrm{Fe}-\mathrm{TiO}_{2} ; \mathrm{Al}_{2} \mathrm{O}_{3}\right)$ were mixed with $\mathrm{AS}$, they could significantly increase the floc size, and the recovery factor was also larger than using AS alone. The strength factor decreased if two new coagulants were used, and the results may be caused by the bridging effects formed by nano particles.
\end{abstract}

(C) 2014 Elsevier B.V. All rights reserved.

\section{Introduction}

Coagulation, sedimentation, and gravity filtration are the traditional drinking water treatment processes [1]. Al-based coagulants were widely used, and they could significantly remove particles and organic matters in the raw water. But the residual Al after coagulation was a large problem for the safety of water quality [2-5]. So

\footnotetext{
* Corresponding author. Tel.: +86 10 62849138; fax: +86 1062849138.

E-mail address: fengxiao@rcees.ac.cn (F. Xiao).
}

how to reduce the concentration of residual $\mathrm{Al}$ in the filtrated water was an important issue in China.

With the development of nano technology, more and more nano particles were applied to remove pollutants [6,7]. Under the low turbidity and the low temperature circumstance, the flocs were not easily formed. In order to improve the coagulation performances, some new coagulants were applied. Titanium dioxide $\left(\mathrm{TiO}_{2}\right)$ is one of the most studied nano-particle for photo-catalytic reactions due to its high activity, chemical stability, robustness against photocorrosion, and low toxicity. Thus before using the titanium dioxide particles, their surfaces should be modified by improving the 

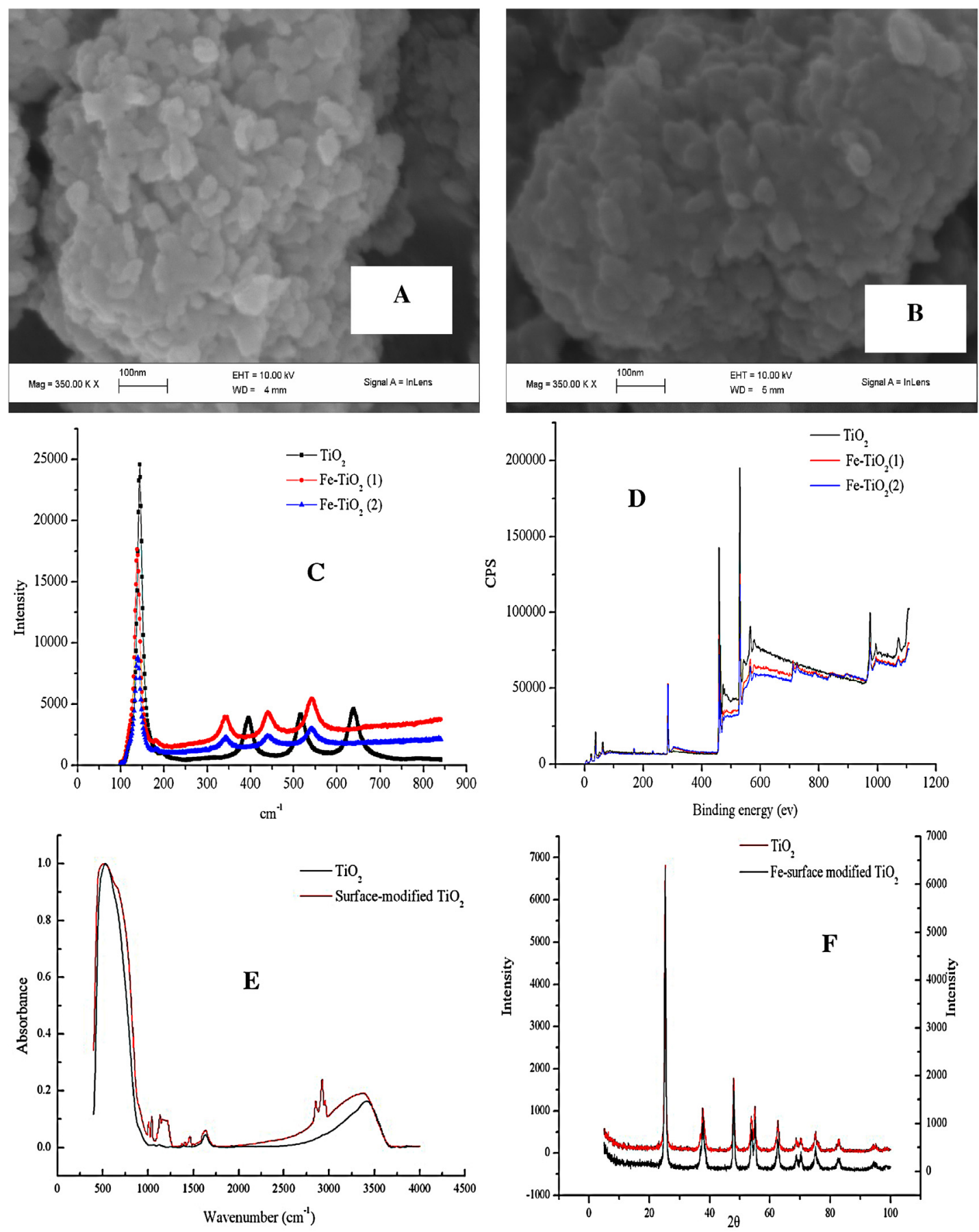

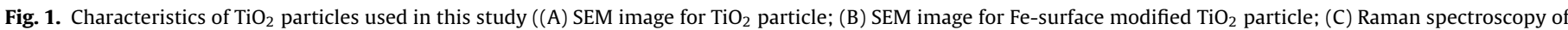

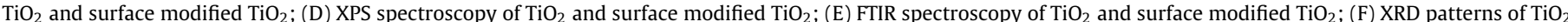
and Fe-surface modified $\mathrm{TiO}_{2}$ particles).

dispersion stability and photochemical stability [8,9]. Fe coating used widely in the surface modification methods. These coating could decrease the photochemical activity, and the stability could also be improved [10-12]. In this research, Fe-surface modified $\mathrm{TiO}_{2}+\mathrm{AS}$ was used to treat the raw water, and the characteristics of flocs were investigated. Aluminum oxide $\left(\mathrm{Al}_{2} \mathrm{O}_{3}\right)$ is currently one of the most useful nano particles for removal of organic matter. In order to better understand the effects of nano-particles on the coagulation behavior, nano- $\mathrm{Al}_{2} \mathrm{O}_{3}+\mathrm{AS}$ and $\mathrm{AS}$ alone were used for comparison.
The breakage and re-growth of flocs have been studied by many researches [13-15]. The floc size, strength and compaction of flocs may significantly affect the efficiency of solid/liquid separation [16]. Floc strength could be measured by applying an increasing shear rate to the preformed flocs and relating the energy dissipation to the broken floc size [17]. Fractal dimension and particle size of flocs are generally recognized as two important physical properties which have significant impacts on the efficiency of unit processes in water treatment works. 

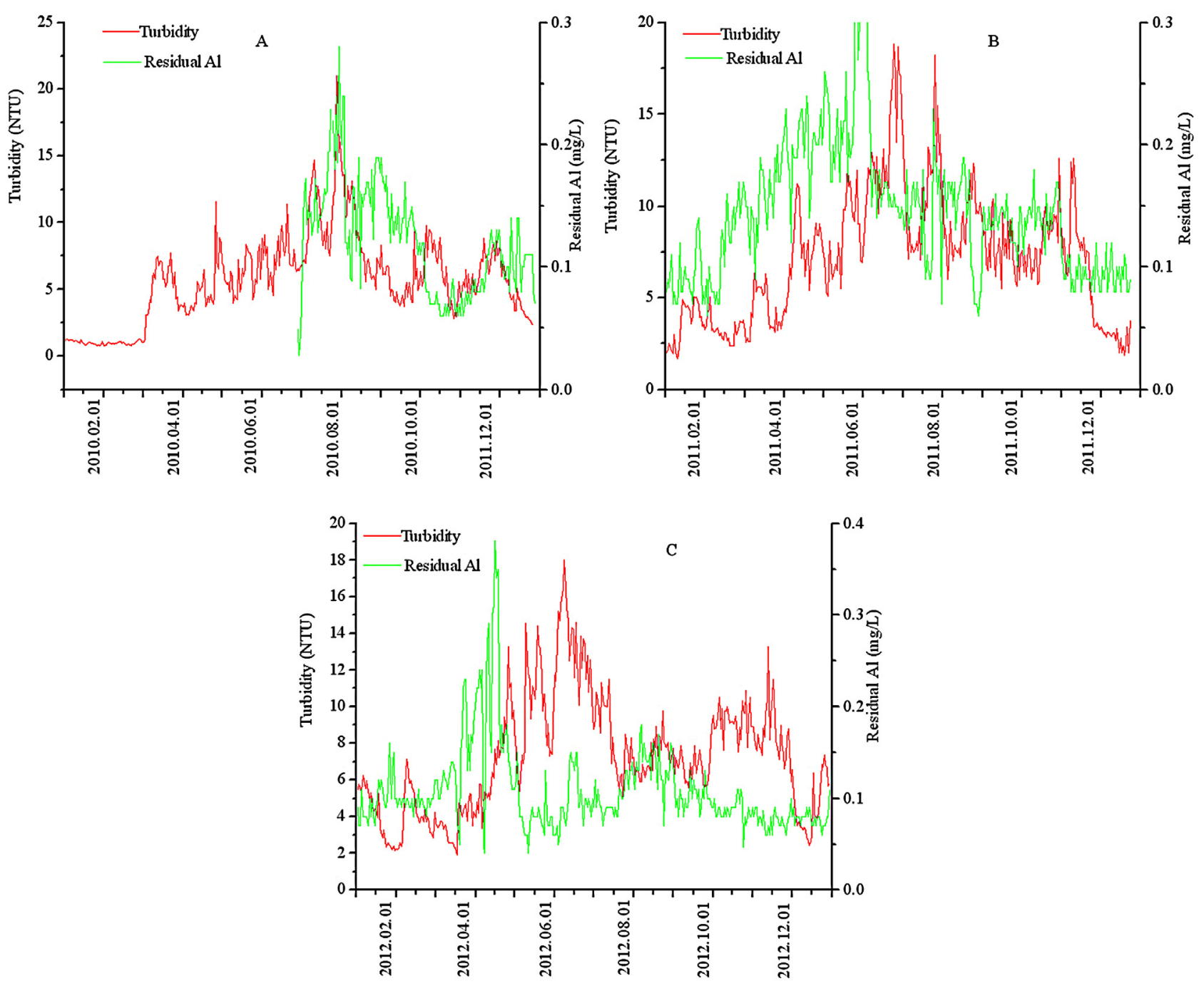

Fig. 2. Relationship between turbidity of raw water and residual $\mathrm{Al}$ ((A) 2010; (B) 2011; (C) 2012).

The objective of this study was: (1) to assess seasonal variability of surface water quality; (2) to understand the relationship between surface water quality parameter and the quality of filtrated water; (3) to investigate the flocs formed by two new coagulants under different coagulation conditions.

\section{Experiments and analytical methods}

\subsection{Plant description and general characteristics of different source waters}

The treatment plant in this study includes the following steps: (1) pre-chlorination; (2) coagulation; (3) sedimentation; (4) filtration through sand and active carbon filters; (5) chlorination for the disinfection of water. The characteristics of source water changed in different seasons, and thus it may affect the coagulation process and residual $\mathrm{Al}$ in the finished water. The basic characteristics of raw water in different seasons are summarized in Table 1.

\subsection{Coagulants used in this study}

Poly-aluminum (PACl) was used in the water treatment plant. Three different coagulants were used to investigate the effects of nano particles on the coagulation process. AS was prepared by dissolving the commercial $\mathrm{Al}_{2}\left(\mathrm{SO}_{4}\right)_{3} \cdot 18 \mathrm{H}_{2} \mathrm{O}$ with de-ionized water.
The other two new coagulants were prepared by adding Fe-surface modified $\mathrm{TiO}_{2}$ particles or $\mathrm{Al}_{2} \mathrm{O}_{3}$ particles to the AS solution. In order to better understand the effects of nano particles on the flocs, five different concentrations of nano particles $(100 \mathrm{mg} / \mathrm{L}, 200 \mathrm{mg} / \mathrm{L}$, $400 \mathrm{mg} / \mathrm{L}, 800 \mathrm{mg} / \mathrm{L}, 1000 \mathrm{mg} / \mathrm{L}$ ) were used. These results of characteristics of flocs were compared with the coagulation process by AS. Al species in AS, AS + Fe- $\mathrm{TiO}_{2}(100 \mathrm{mg} / \mathrm{L}), \mathrm{AS}+\mathrm{Al}_{2} \mathrm{O}_{3}(100 \mathrm{mg} / \mathrm{L})$ were characterized by Ferron method, and the results are summarized in Table 2.

Table 1

Characteristics for different water sources during the research.

\begin{tabular}{lcccc}
\hline Time & DOC $(\mathrm{mg} / \mathrm{L})$ & $\mathrm{UV}_{254}\left(\mathrm{~cm}^{-1}\right)$ & Turbidity $(\mathrm{NTU})$ & SUVA $\left(\mathrm{cm}^{-1} \mathrm{~L} / \mathrm{mg}\right)$ \\
\hline Spring & $2.25 \pm 0.31$ & $0.0351 \pm 0.009$ & $6.94 \pm 5.21$ & $1.56 \pm 0.03$ \\
Summer & $3.12 \pm 0.48$ & $0.0384 \pm 0.007$ & $9.28 \pm 2.37$ & $1.2308 \pm 0.04$ \\
Autumn & $2.75 \pm 0.33$ & $0.0472 \pm 0.005$ & $7.16 \pm 3.18$ & $1.76164 \pm 0.03$ \\
Winter & $2.36 \pm 0.29$ & $0.0314 \pm 0.008$ & $4.88 \pm 2.54$ & $1.3305 \pm 0.18$ \\
\hline
\end{tabular}

Table 2

$\mathrm{Al}$ species in $\mathrm{AS}, \mathrm{AS}+\mathrm{Fe}-\mathrm{TiO}_{2}(100 \mathrm{mg} / \mathrm{L}), \mathrm{AS}+\mathrm{Al}_{2} \mathrm{O}_{3}(100 \mathrm{mg} / \mathrm{L})$.

\begin{tabular}{|c|c|c|c|}
\hline & $\mathrm{Al}_{\mathrm{a}}$ & $\mathrm{Al}_{\mathrm{b}}$ & $\mathrm{Al}_{\mathrm{c}}$ \\
\hline AS & $93.78 \%$ & $6.22 \%$ & 0 \\
\hline $\mathrm{Fe}-\mathrm{TiO}_{2}+\mathrm{AS}$ & $86.24 \%$ & $8.29 \%$ & $5.47 \%$ \\
\hline Nano- $\mathrm{Al}_{2} \mathrm{O}_{3}+\mathrm{AS}$ & $87.13 \%$ & $11.23 \%$ & $1.64 \%$ \\
\hline
\end{tabular}




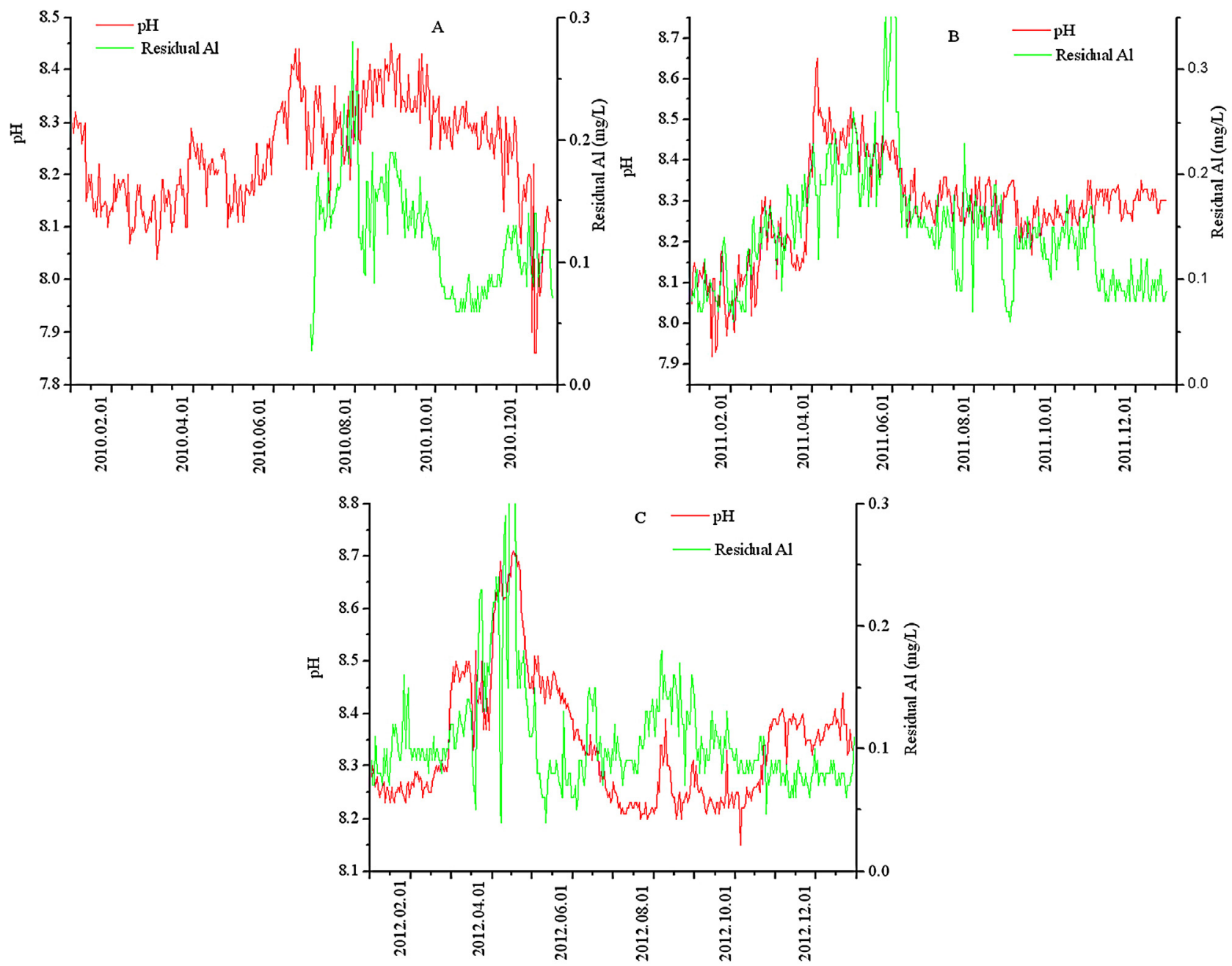

Fig. 3. Relationship between pH of raw water and residual Al ((A) 2010; (B) 2011; (C) 2012).

\subsection{Characterization of nano particles used in this study}

$\mathrm{TiO}_{2}$ and Fe-surface modified $\mathrm{TiO}_{2}$ particles were identified by X-ray diffraction using a Shimadzu XRD 6000 power (Japan). Raman spectra were examined by a Laser Raman spectrophotometer (Renishaw RM 1000, UK). X-ray photoelectron spectroscopy data was obtained with Phobios 100 electron analyzer using an Mg X-ray source (PHI 5300, USA). The morphology of $\mathrm{TiO}_{2}$ was measured by Field emission scanning electron microscope (Hitachi S-4800, Japan).

\subsection{Field survey}

The quality of raw water and treated water were examined and controlled by the use of on-line meters, as well as with regular laboratory tests. These on-line measurements comprise of $\mathrm{pH}$, turbidity and temperature. These on-line values were monitored, recorded and controlled electronically.

\subsection{Laboratory experiments}

\subsubsection{Floc breakage and re-growth}

A laser diffraction instrument (Mastersizer 2000) was used to measure dynamic floc size as the coagulation proceeded.
The strength factor $\left(S_{\mathrm{f}}\right)$ and recovery factor $\left(R_{\mathrm{f}}\right)$ are calculated as follows [18]:

$S_{\mathrm{f}}=\frac{d_{2}}{d_{1}} \times 100$

$R_{\mathrm{f}}=\frac{d_{3}-d_{2}}{d_{1}-d_{2}} \times 100$

The $d_{1}, d_{2}$ and $d_{3}$ are the average size of flocs at the steady phase before breakage, after the breakage and after re-growth.

When the effects of breakage rate on the floc size were investigated, the breakage rate was increased to $75,100,150,200,300 \mathrm{rpm}$ for $5 \mathrm{~min}$, followed by another slow mixing ( $40 \mathrm{rpm}$ ) for $10 \mathrm{~min}$ for flocs to re-grow. The concentration of nano particles used in this study was $1000 \mathrm{mg} / \mathrm{L}$. The relationship between the applied shear and broken floc size has been used by many researchers to evaluate the floc strength as described in former studies [19-22]:

$\log d=\log C=\gamma \log (\mathrm{rpm})$

where $d$ is the broken floc size $(\mu \mathrm{m}), \gamma$ is stable floc size exponent, rpm is the imposed shear speed. The broken floc size $d$ after $5 \mathrm{~min}$ shear was plotted against rpm on a log-log scale, and the slope of the line indicated the rate of the degradation. The $\gamma$ represented the floc strength. A larger $\gamma$ was an indication of the flocs that are more prone to break into smaller sizes with the increase of shear force. 


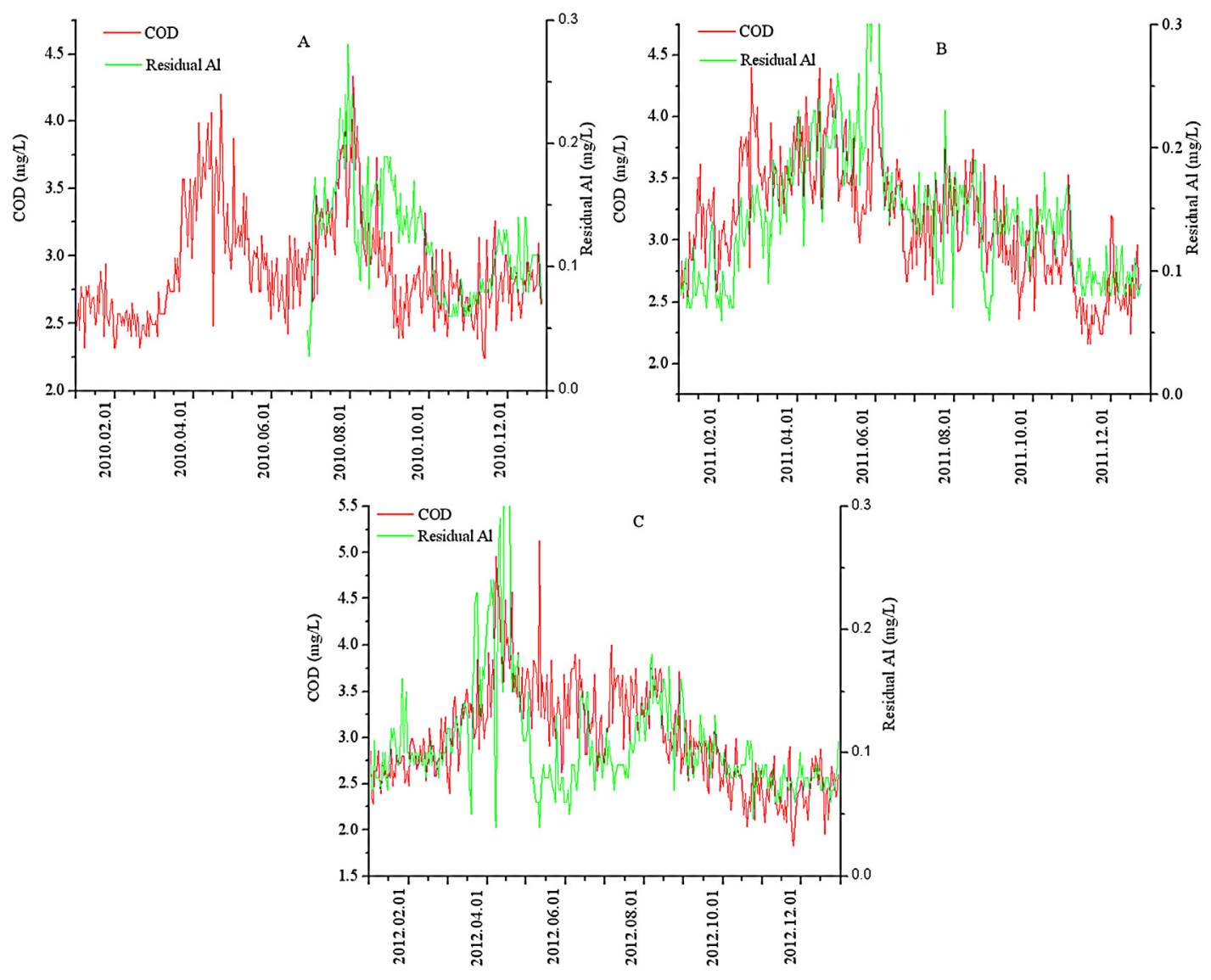

Fig. 4. Relationship between COD of raw water and residual Al ((A) 2010; (B) 2011; (C) 2012 ).

When the effects of concentration of nano particles on characteristics of flocs were investigated, the flocs were exposed to $200 \mathrm{rpm}$ for $5 \mathrm{~min}$. In order better understand the effects of nano particles on the coagulation process, five concentrations of nano particles ( $100 \mathrm{mg} / \mathrm{L}, 200 \mathrm{mg} / \mathrm{L}, 400 \mathrm{mg} / \mathrm{L}, 800 \mathrm{mg} / \mathrm{L}, 1000 \mathrm{mg} / \mathrm{L}$ ) in AS were applied. The flocs formed by AS were used to be compared. When the effects of breakage period were investigated, the flocs were exposed to $200 \mathrm{rpm}$ for $1 \mathrm{~min}, 5 \mathrm{~min}$ or $10 \mathrm{~min}$, and the concentration of nano particles was $100 \mathrm{mg} / \mathrm{L}$.

\subsubsection{Floc fractal structure analysis and floc growth rate}

A brief description is given here of the widely used light scattering method for the determination of aggregate mass fractal dimension [23]. The light scattering technique involves measurement of light intensity $I$ as a function of the scatter vector $Q$. For independently scattering aggregates, the relationship among $I, Q$ and the fractal dimension $D_{\mathrm{f}}$ can be represented by Eq. (4):

$I \propto Q^{D_{\mathrm{f}}}$

The relationship shown in Eq. (4) indicated the determination of $D_{\mathrm{f}}$, which could be given by the slope of $\log I$ versus $\log Q$ by fitting a straight line.

The growth rate was calculated by the slope of the rapid growth region as Eq. (5),

Growth rate $=\frac{D_{\mathrm{t}}-D_{\mathrm{s}}}{\Delta \mathrm{t}}$

The $D_{\mathrm{t}}$ and $D_{\mathrm{s}}$ are the average size of flocs at the steady phase before breakage and the initial particle size.

\section{Results and discussion}

3.1. The characteristics of $\mathrm{TiO}_{2}$ and Fe-surface modified $\mathrm{TiO}_{2}$

The characteristics of $\mathrm{TiO}_{2}$ particles were summarized in Fig. 1, and $\mathrm{Fe}-\mathrm{TiO}_{2}(1)$ and $\mathrm{Fe}-\mathrm{TiO}_{2}(2)$ are two nano particles with

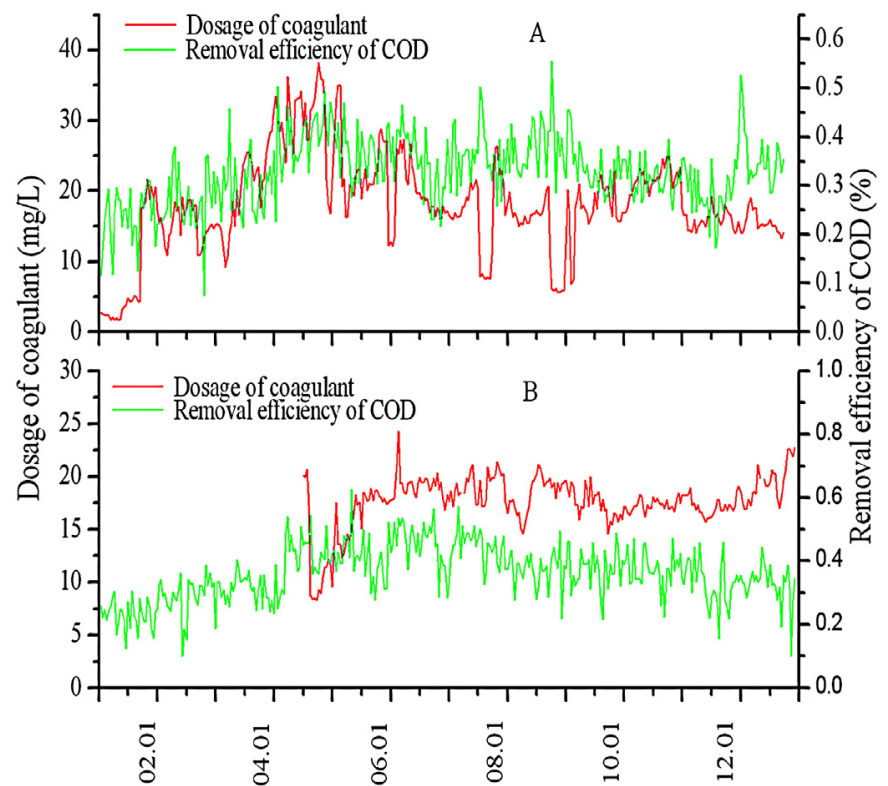

Fig. 5. Relationship between coagulant dosage and the removal efficiency of COD ((A) 2011; (B) 2012). 

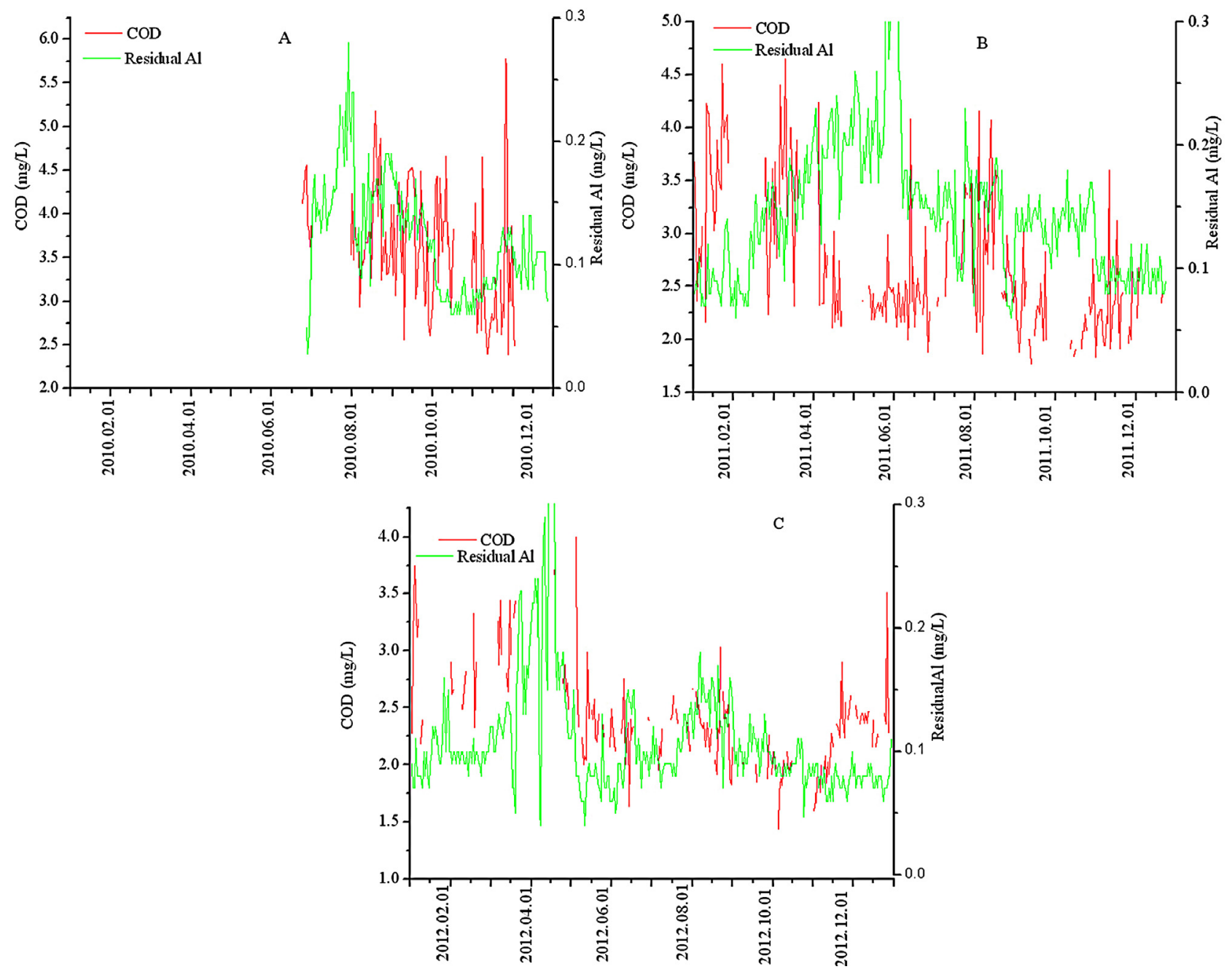

Fig. 6. Relationship between COD of raw water in Yellow River and residual Al ((A) 2010; (B) 2011; (C) 2012).

different amounts of Fe oxide. Fig. $1 \mathrm{~A}$ and $\mathrm{B}$ showed that pure $\mathrm{TiO}_{2}$ with a diameter of $30 \mathrm{~nm}$, and the Fe-surface modified $\mathrm{TiO}_{2}$ had a larger diameter $(40 \mathrm{~nm})$. Fig. $1 \mathrm{C}$ indicated that the addition of Feoxide resulted in the decrease Raman intensity, and the larger the amount of Fe oxide loaded, the weaker the Raman band becomes. Fig. 1D showed that the peak intensity of $\mathrm{Ti}$ and $\mathrm{O}$ decreased, and these results indicated that the surface of $\mathrm{TiO}_{2}$ was covered by Feoxide. The $\mathrm{Fe}-\mathrm{O}$ vibration and $\mathrm{Fe}-\mathrm{O}$ stretching are demonstrated by the bands at $892 \mathrm{~cm}^{-1}, 809 \mathrm{~cm}^{-1}$ and $549 \mathrm{~cm}^{-1}, 457 \mathrm{~cm}^{-1}$ as shown in Fig. 1E. The XRD patterns of $\mathrm{TiO}_{2}$ and Fe-surface modified $\mathrm{TiO}_{2}$ showed in Fig. $1 \mathrm{~F}$ indicated that surface modification had no significant effects on the crystal of $\mathrm{TiO}_{2}$.

\subsection{Relationship between turbidity of raw water and residual Al}

The relationship between the turbidity of raw water and residual $\mathrm{Al}$ in the past three years was summarized in Fig. 2.
The results in Fig. 2 indicated that the variation tendency of the turbidity of raw water was almost the same in the past three years. The turbidity of raw water was low at the beginning of every year, and it increased with the increasing of temperature. It is a very typical phenomenon in China. During the summer season, the consumption of the water should be increased sharply because the summer is the production season. And also the source water was a reservoir which received the water from the Yellow river with a high turbidity. Due to the high demand of the water, the retention time (RT) for the reservoir should be reduced significantly, thus with the temperature increased, the turbidity increased. Another reason is during the summer the reservoir should be affected by some algae due to the increase of the temperature, leading to a high turbidity. The concentration of residual Al may be larger when the raw water with low turbidity and low temperature was treated. But the relationship between the turbidity and residual $\mathrm{Al}$ indicated that the peak value of residual Al was at summer. This may be

Table 3

Analysis of different characteristics of raw water and characteristics of finished water.

\begin{tabular}{|c|c|c|c|c|c|c|}
\hline & \multicolumn{2}{|c|}{2010} & \multicolumn{2}{|l|}{2011} & \multicolumn{2}{|l|}{2012} \\
\hline & 1 & 2 & 1 & 2 & 1 & 2 \\
\hline Turbidity and residual alum & - & 0.471 & 0.427 & 0.328 & -0.171 & -0.085 \\
\hline $\mathrm{pH}$ and residual alum & - & 0.137 & 0.731 & -0.244 & 0.579 & 0.228 \\
\hline COD and residual alum & - & 0.509 & 0.560 & 0.536 & 0.351 & 0.511 \\
\hline COD removal efficiency and coagulant dosage & - & - & 0.592 & -0.280 & - & -0.084 \\
\hline COD in yellow river and residual alum & & -0.004 & -0.031 & 0.101 & -0.129 & 0.009 \\
\hline
\end{tabular}


Table 4

Characteristics of flocs formed in these coagulation processes.

\begin{tabular}{|c|c|c|c|c|c|}
\hline Coagulants & Strength factor (\%) & Recovery factor (\%) & Fractal dimension 1 & Fractal dimension 2 & Fractal dimension 3 \\
\hline AS & 49.68 & 71.42 & 2.431 & 2.6706 & 2.6012 \\
\hline $\mathrm{AS}+(100 \mathrm{mg} / \mathrm{L}) \mathrm{Fe}-\mathrm{TiO}_{2}$ & 43.12 & 76.23 & 2.2602 & 2.5119 & 2.4261 \\
\hline $\mathrm{AS}+(200 \mathrm{mg} / \mathrm{L}) \mathrm{Fe}-\mathrm{TiO}_{2}$ & 39.12 & 77.15 & 2.2105 & 2.4967 & 2.4039 \\
\hline $\mathrm{AS}+(400 \mathrm{mg} / \mathrm{L}) \mathrm{Fe}-\mathrm{TiO}_{2}$ & 37.58 & 77.25 & 2.1954 & 2.4762 & 2.3894 \\
\hline $\mathrm{AS}+(800 \mathrm{mg} / \mathrm{L}) \mathrm{Fe}-\mathrm{TiO}_{2}$ & 34.25 & 78.25 & 2.1741 & 2.4535 & 2.3754 \\
\hline $\mathrm{AS}+(1000 \mathrm{mg} / \mathrm{L}) \mathrm{Fe}-\mathrm{TiO}_{2}$ & 32.86 & 79.23 & 2.1391 & 2.4293 & 2.3597 \\
\hline $\mathrm{AS}+(100 \mathrm{mg} / \mathrm{L}) \mathrm{Al}_{2} \mathrm{O}_{3}$ & 45.98 & 73.46 & 2.3561 & 2.6033 & 2.5353 \\
\hline $\mathrm{AS}+(200 \mathrm{mg} / \mathrm{L}) \mathrm{Al}_{2} \mathrm{O}_{3}$ & 42.18 & 74.65 & 2.3264 & 2.5867 & 2.5124 \\
\hline $\mathrm{AS}+(400 \mathrm{mg} / \mathrm{L}) \mathrm{Al}_{2} \mathrm{O}_{3}$ & 39.35 & 77.25 & 2.2964 & 2.5547 & 2.5056 \\
\hline $\mathrm{AS}+(800 \mathrm{mg} / \mathrm{L}) \mathrm{Al}_{2} \mathrm{O}_{3}$ & 37.12 & 78.25 & 2.2758 & 2.5437 & 2.5193 \\
\hline $\mathrm{AS}+(1000 \mathrm{mg} / \mathrm{L}) \mathrm{Al}_{2} \mathrm{O}_{3}$ & 35.18 & 79.46 & 2.2355 & 2.5345 & 2.4936 \\
\hline
\end{tabular}

caused by the humic acid and organic matter with smaller molecular weight. So in the treatment process, the organic component was an important factor. In the former treatment process, the turbidity was used to determine the coagulant dosage, but the results in this study showed that some other characteristics of raw water should also be investigated to determine the coagulation process.

\subsection{Relationship between the residual Al and $\mathrm{pH}$ of raw water}

The relationship between the residual $\mathrm{Al}$ and $\mathrm{pH}$ of raw water in past three years were summarized in Fig. 3.

As explained in Section 3.2, the turbidity was affected by temperature. The $\mathrm{pH}$ value of source water reached the largest during May-September. Because the source water was pumped from the Yellow River, the characteristics of raw water were affected by the precipitation. The precipitation was less in winter, and the

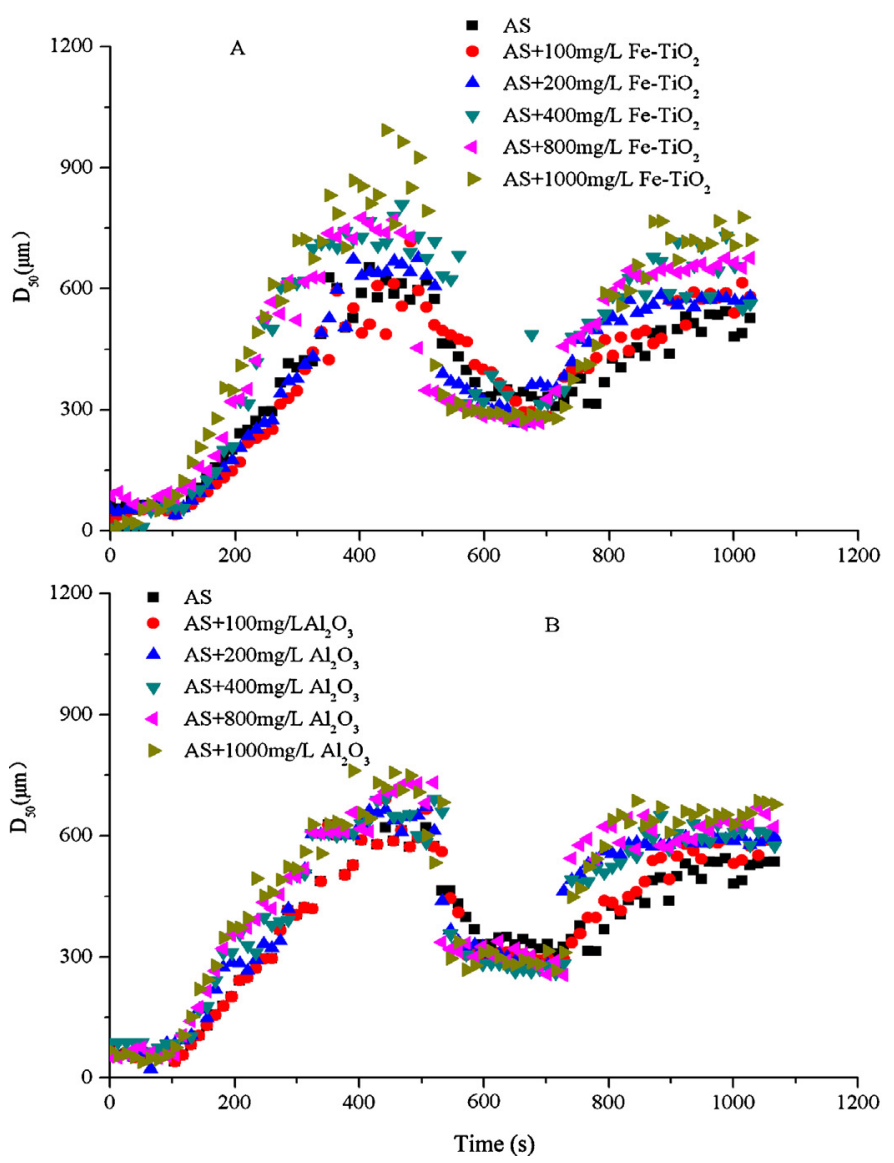

Fig. 7. Floc sizes in the coagulation process using different coagulants with different concentration of nano particles $\left((\mathrm{A}) \mathrm{AS}+\mathrm{Fe}-\mathrm{TiO}_{2}\right.$; (B) $\left.\mathrm{AS}+\mathrm{Al}_{2} \mathrm{O}_{3}\right)$. correlation between $\mathrm{pH}$ value and precipitation was not significant. The $\mathrm{pH}$ values increased with increasing the precipitation during April-August, and $\mathrm{pH}$ values decreased with decreasing the precipitation during August-November. These results indicated that the $\mathrm{pH}$ value was affected by precipitation, and the variation was in accordance with the precipitation. The precipitation would bring the alkaline substances from the earth surface system to increase the $\mathrm{pH}$ value of the water. In the coagulation-flocculation process, $\mathrm{Al}_{\mathrm{a}}$ is mainly composed of monomer and some small polymers. It complexes with negatively functional groups, and neutralize some large NOM and particle to form insoluble Al-NOM. While most of the NOM in natural water is not large enough to provide nuclei for floc formation with $\mathrm{Al}_{\mathrm{a}}$, the complex of $\mathrm{Al}_{\mathrm{a}}-\mathrm{NOM}$ is soluble and is not large enough to settle down. Previous works stated that the diameter of $\mathrm{Al}_{\mathrm{b}}$ molecule is a few nanometers [24,25], so it not only shows high effectiveness in neutralizing the negative charge of colloids and NOM, but can also act as nuclear to form floc with soluble NOM to produce colloids and precipitate efficiently [26].

\subsection{Relationship between the residual Al and the COD of raw water}

The relationship between the residual $\mathrm{Al}$ and the COD value of raw water in past three years were summarized in Fig. 4.

The results in Fig. 4 showed that when the value of COD increased, the residual $\mathrm{Al}$ also increased. They are presented the strictly positive correlation. In April, May, August, September, the concentration of COD has a significant increase, and the residual Al in the filtrated water also reached the peak value.

COD (chemical oxygen demand) is the total measurement of all chemicals (organics \& in-organics) in the water. It uses strong chemical agent to degrade both the organic as well as inorganic matter present in the water samples. The organic matter such as humic acid was also included [27,28], and these results also indicated that the organic matter in raw water had significant effects on residual $\mathrm{Al}$.

\subsection{Relationship between dosage of coagulant and the removal efficiency of COD}

The relationship between the coagulant dosage and the removal efficiency of COD in past three years were summarized in Fig. 5.

Coagulant dosage may significantly affect the coagulation performance. The results in Fig. 5 showed that the removal efficiency of COD was not significantly related to the coagulant dosage. When the coagulant dosage was 2 or 3 times than former, the increase of removal efficiency for COD was not significant. In the results of 2012, the removal efficiency for COD was changed from 30\% to $45 \%$ although the dosage of coagulant was $20 \mathrm{mg} / \mathrm{L}$. These results indicated that the remove efficiency for COD was not correlated with the dosage of coagulant. The results in Section 3.4 showed that the COD value of raw water had significant relationship with residual 

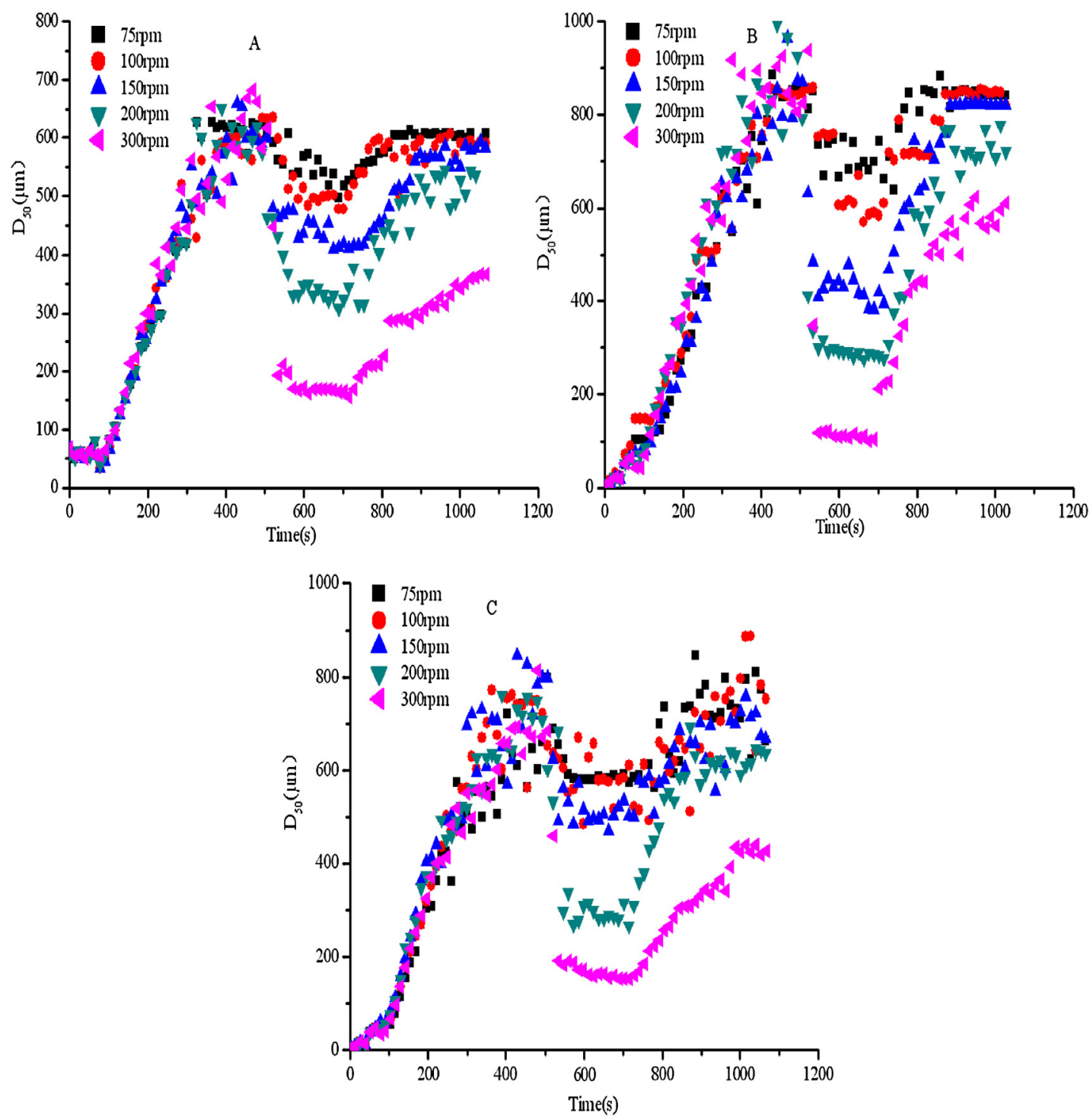

Fig. 8. Floc sizes in the coagulation process using different coagulants under different breakage rate $\left((A) A S ;(B) A S+F e-T i O_{2} ; A S+\mathrm{Al}_{2} \mathrm{O}_{3}\right)$.

Al. So how to reduce the COD value may be the focus in the latter study.

\subsection{Relationship between the COD of raw water in the Yellow River and residual $\mathrm{Al}$}

The relationship between the COD of raw water in the Yellow River and residual $\mathrm{Al}$ in past three years were summarized in Fig. 6.

The results indicated that the correlation between the COD of raw water in the Yellow River and residual $\mathrm{Al}$ in filtrated water was not significant in 2010 and 2011, so the characteristics of raw water in reservoir not in the Yellow River should be investigated to direct the operation process.

\subsection{Statistic analysis}

The relationship described in Sections 3.2-3.6 was analyzed in SPSS. The results of statistic analysis were summarized in Table 3.

For acceptance of a valid relationship, both a high correlation factor and a probability value less than 0.05 (95\% confidence of a real correlation) were deemed necessary. As a result, a correlation with COD with residual Al could be identified. It can be seen that there is some relationship between the water sources that showed both higher COD produce higher residual $\mathrm{Al}$. In the former study, $\mathrm{pH}$ was considered to be a detrimental factor influencing the residual Al. But the results in Table 3 indicated that the relationship was significant in the first half-year. The relationship was not significant in the latter half of the year. So the residual $\mathrm{Al}$ in the finished water was affected by many factors, and COD will be the most important factor. The relationship between COD in the Yellow River and residual Al was not significant in all three years, so it was not recommended to be monitored.

\subsection{Characteristics of flocs formed in the coagulation progress}

\subsubsection{Effects of nano particles on the coagulation process}

The floc sizes in the coagulation process using different coagulants are summarized in Fig. 7.

The results in Fig. 7 indicated that the addition of nano particles could significantly increase the floc size after growth. With increasing the concentration of nano particles from $0 \mathrm{mg} / \mathrm{L}$ to $1000 \mathrm{mg} / \mathrm{L}$, the floc size increased from to. $620 \mu \mathrm{m}$ to $850 \mu \mathrm{m}$ for $\mathrm{AS}+\mathrm{Fe}-\mathrm{TiO}_{2}$, and from $620 \mu \mathrm{m}$ to $750 \mu \mathrm{m}$ for $\mathrm{AS}+\mathrm{Al}_{2} \mathrm{O}_{3}$. The particles concentration in water was small, so the coagulation process was hindered. 
Table 5

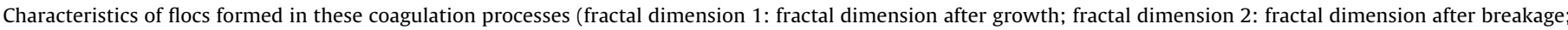
fractal dimension 3: fractal dimension after re-growth).

\begin{tabular}{|c|c|c|c|c|c|c|}
\hline Coagulants & Breakage rate (rpm) & Strength factor (\%) & Recover factor (\%) & Fractal dimension 1 & Fractal dimension 2 & Fractal dimension 3 \\
\hline \multirow{5}{*}{ AS } & 75 & 80.17 & 86.58 & \multirow{5}{*}{2.431} & 2.4996 & 2.5147 \\
\hline & 100 & 75.95 & 84.18 & & 2.538 & 2.5405 \\
\hline & 150 & 65.98 & 82.5 & & 2.6301 & 2.6221 \\
\hline & 200 & 49.68 & 71.42 & & 2.6706 & 2.6012 \\
\hline & 300 & 26.61 & 42.74 & & 2.7148 & 2.6547 \\
\hline \multirow{5}{*}{$\mathrm{AS}+\mathrm{Fe}-\mathrm{TiO}_{2}$} & 75 & 75.08 & 99.11 & \multirow{5}{*}{2.1391} & 2.1906 & 2.2583 \\
\hline & 100 & 67.08 & 98.21 & & 2.2647 & 2.2441 \\
\hline & 150 & 50.15 & 93.57 & & 2.3442 & 2.3058 \\
\hline & 200 & 32.86 & 79.23 & & 2.4293 & 2.3597 \\
\hline & 300 & 12.07 & 64.13 & & 2.4298 & 2.3499 \\
\hline \multirow{5}{*}{$\mathrm{AS}+\mathrm{Al}_{2} \mathrm{O}_{3}$} & 75 & 77.29 & 100 & \multirow{5}{*}{2.2355} & 2.3162 & 2.4232 \\
\hline & 100 & 69.42 & 100 & & 2.413 & 2.4092 \\
\hline & 150 & 55.12 & 90.12 & & 2.4805 & 2.4336 \\
\hline & 200 & 35.18 & 79.46 & & 2.5345 & 2.4936 \\
\hline & 300 & 20.28 & 53.28 & & 2.5821 & 2.5113 \\
\hline
\end{tabular}

The addition of nano particles could improve the coagulation process through increasing the particles concentration in raw water.

The fractal dimension, recovery factor and strength factor in different coagulation process are summarized in Table 4.

The results in Table 4 showed that the addition of nano particles could significantly decrease the strength factor with increasing the concentration of nano particles. The results indicated that nano particles could bridge the initial particles together, and larger flocs had smaller fractal dimension. The bridging force formed by nano particles was small, so the strength factor decreased with increasing the concentration of nano particles. The results of recovery factor showed that the recovery factor increased with increasing the concentration of nano particles.

\subsubsection{Effects of high shear on floc breakage and re-growth}

The $\mathrm{D}_{50}$ decreased with the increasing shear force in all experiment conditions, and the results are summarized in Fig. 8. The fractal dimension, recovery factor and strength factor in different coagulation process are summarized in Table 5.

The results in Table 5 indicated that the addition of nano particles could significantly decrease the strength factor. The recovery factor increased due to bridging effects caused by nano particles. The results of fractal dimension indicated that the addition of nano particles decreased the fractal dimension, and the fractal dimension after breakage increased with increasing the breakage rate.

To quantitatively compare the difference of three coagulants in the response of floc $D_{50}$ to increase shear, $D_{50}$ of the broken flocs after 5 min shear was plotted against the rpm on a log-log scale. The results are summarized in Fig. 9. It can be found that a straight line could be drawn through the data. As mentioned above, the slope of the line indicated that the degradation rate of the floc size. The larger the slope was, the weaker the floc was. The results in Fig. 9 showed that the slope for $\mathrm{AS}, \mathrm{AS}+\mathrm{Fe}-\mathrm{TiO}_{2}$ and $\mathrm{AS}+\mathrm{Al}_{2} \mathrm{O}_{3}$ was $1.51125,1.96219,2.41109$, respectively. So the flocs formed by AS had the largest strength factor, which was consistent with the former study. The nano particles played a bridging effects during the coagulation process.

\subsubsection{Effects of breakage period on floc breakage and re-growth}

In all cases, the floc size immediately decreased with the increasing shear as shown in Fig. 10. The strength factor, recovery factor, flocs growth rate and fractal dimension were summarized in Table 6.
The results in Fig. 10 showed that the addition of nano particles could significantly increase the floc size and flocs growth rate, and this maybe caused by the bridging effects of nano particles existed in the solution. The three floc sizes were $620 \mu \mathrm{m}, 660 \mu \mathrm{m}, 680 \mu \mathrm{m}$ for $\mathrm{AS}, \mathrm{AS}+\mathrm{Fe}-\mathrm{TiO}_{2}$ and $\mathrm{AS}+\mathrm{Al}_{2} \mathrm{O}_{3}$. The floc size after breakage decreased with increasing the breakage period.

The results in Table 6 indicated that the addition of nano particles could decrease the fractal dimension. These results indicated that the bridging effects between particles formed by nano particles, and the strength factor also verified these results. Because the bridging force between particles was smaller, the strength factor decreased when using two new coagulants. When the breakage period was $1 \mathrm{~min}$, the recovery factor has no significant difference between the three coagulants. When the breakage period was $10 \mathrm{~min}$, the recovery factor used $\mathrm{AS}+\mathrm{Fe}-\mathrm{TiO}_{2}$ and $\mathrm{AS}+\mathrm{Al}_{2} \mathrm{O}_{3}$ was $65.64 \%$ and $65.31 \%$, which was larger than using AS (59.52\%). For the same coagulant, the results indicated that a reduction in the time exposed to a similar shear showed both a significant decrease in floc breakage and an increase in floc re-growth.

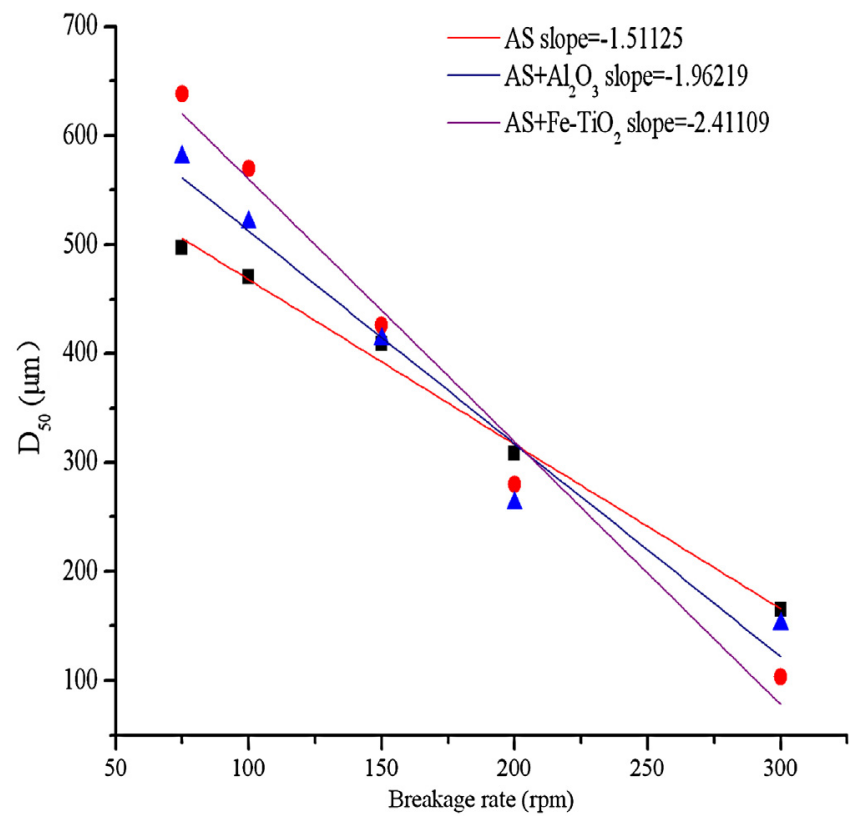

Fig. 9. The log-log curves of stable flocs size decreasing with rotary rate. 

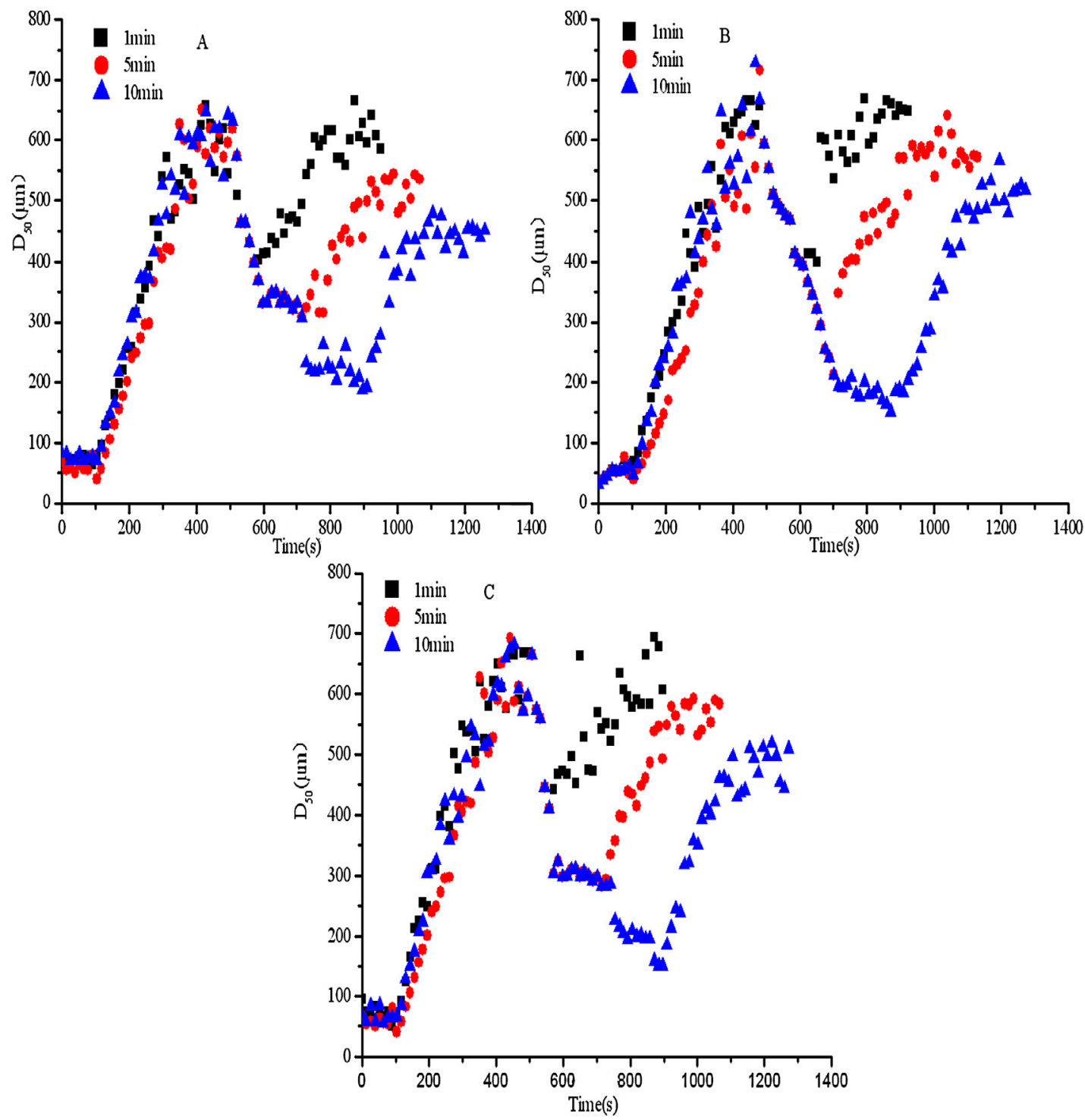

Fig. 10. Floc sizes in the coagulation process using different coagulants under different breakage period $\left((A) A S ;(B) A S+F e-T i O_{2} ; A S+A l_{2} O_{3}\right)$.

Table 6

Strength factor, recovery factor and fractal dimension in the coagulation progress (fractal dimension 1: fractal dimension after growth; fractal dimension 2: fractal dimension after breakage; fractal dimension 3: fractal dimension after re-growth).

\begin{tabular}{|c|c|c|c|c|c|c|c|}
\hline Coagulants & $\begin{array}{l}\text { Breakage } \\
\text { period (min) }\end{array}$ & $\begin{array}{l}\text { Strength factor } \\
(\%)\end{array}$ & $\begin{array}{l}\text { Recovery factor } \\
(\%)\end{array}$ & $\begin{array}{l}\text { Growth rate } \\
(\mu \mathrm{m} / \mathrm{s})\end{array}$ & $\begin{array}{l}\text { Fractal } \\
\text { dimension } 1\end{array}$ & $\begin{array}{l}\text { Fractal } \\
\text { dimension } 2\end{array}$ & $\begin{array}{l}\text { Fractal } \\
\text { dimension } 3\end{array}$ \\
\hline \multirow{3}{*}{ AS } & 1 & 64.19 & 94.57 & \multirow{3}{*}{1.55} & \multirow{3}{*}{2.4231} & 2.6241 & 2.5513 \\
\hline & 5 & 49.68 & 71.42 & & & 2.6706 & 2.6012 \\
\hline & 10 & 32.22 & 59.52 & & & 2.7282 & 2.6398 \\
\hline \multirow{3}{*}{$\begin{array}{l}\mathrm{AS}+\mathrm{Fe}- \\
\mathrm{TiO}_{2}\end{array}$} & 1 & 59.18 & 98.12 & \multirow{3}{*}{1.65} & \multirow{3}{*}{2.2602} & 2.4287 & 2.4083 \\
\hline & 5 & 43.12 & 76.23 & & & 2.5119 & 2.4261 \\
\hline & 10 & 23.12 & 65.64 & & & 2.5248 & 2.4654 \\
\hline \multirow{3}{*}{$\mathrm{AS}+\mathrm{Al}_{2} \mathrm{O}_{3}$} & 1 & 60.18 & 93.75 & \multirow{3}{*}{1.7} & \multirow{3}{*}{2.3561} & 2.5016 & 2.4817 \\
\hline & 5 & 45.98 & 73.46 & & & 2.6033 & 2.5353 \\
\hline & 10 & 22.18 & 65.31 & & & 2.6392 & 2.5862 \\
\hline
\end{tabular}

\section{Conclusions}

In this paper, the operation of water treatment plant was investigated, and the coagulation process using two new coagulants were also compared with AS. From the results described previously, some conclusions could be summarized:
1. The raw water was pre-reserved in reservoir, so in the operation process, the characteristics of raw water in reservoir should be investigated. The peak value of residual $\mathrm{Al}$ was at summer. This may be caused by the higher concentration of DOC in the raw water. COD value and residual Al presented the strictly positive correlation, and the COD value of raw water should be 
monitored in the operation process. In addition, $\mathrm{pH}$ values may be an important factor which affects the coagulation process, but it was not the determined factor through the year.

2. The flocs formed by coagulants with nano particles had larger sizes, smaller strength factor and larger recovery factor. The growth rate was increased with increasing the concentration of nano particles, and these results indicated that the nano particles could bridge the flocs together.

\section{Acknowledgments}

This research was supported by the National Basic Research Program (973 Program, Grant No. 2011CB933704), the National Natural Science Foundation of China (Nos. 51378014, 51138008, 51025830,51221892 ) and the six talent peaks program from Jiangsu province (No. JNHB-012).

\section{References}

[1] A. Zouboulis, G. Traskas, P. Samaras, Comparison of single and dual media filtration in a full-scale drinking water treatment plant, Desalination 213 (2007) 334-342.

[2] R.P. Liu, L.J. Zhu, W.X. Gong, H.C. Lan, H.J. Liu, J.H. Qu, Effects of fluoride on coagulation performance of aluminum chloride towards kaolin suspension, Colloids Surf. A 421 (2014) 84-90.

[3] Z.L. Yang, B.Y. Gao, Q.Y. Yue, Coagulation performance and residual aluminum speciation of $\mathrm{Al}_{2}\left(\mathrm{SO}_{4}\right)_{3}$ and polyaluminum chloride (PAC) in the Yellow River water treatment, Chem. Eng. J. 165 (2010) 122-132.

[4] Z.L. Yang, B.Y. Gao, Y. Wang, X.X. Zhang, Q.Y. Yue, Relationship between residual Al species, floc operational parameters and coagulation performance during reservior water, Sep. Purif. Technol. 102 (2013) 147-156.

[5] Z.L. Yang, B.Y. Gao, B.C. Cao, W.Y. Xu, Q.Y. Yue, Effect of $\mathrm{OH}^{-} / \mathrm{Al}^{3+}$ ratio on the coagulation and residual aluminum speciation of polyaluminum chloride (PAC) in surface water treatment, Sep. Purif. Technol. 80 (2011) 59-66.

[6] W. Choi, A. Termin, M.R. Hoffmann, The role of metal ion dopants in quantum-sized $\mathrm{TiO}_{2}$ : correlation between photoreactivity and charge carrier recombination dynamics, J. Phy. Chem. 98 (1994) 13669-13679.

[7] J. Wang, W.H. Xu, L. Chen, X.H. Huang, J.H. Liu, Preparation and evaluation of magnetic nanoparticles impregnated chitosan beads for arsenic removal from water, Chem. Eng. J. 251 (2014) 25-34.

[8] H.G. Yu, H. Irie, Y. Shimodaira, Y. Hosogi, Y. Kuroda, M. Miyauchi, K. Hashimoto, An efficient visible-light-sensitive $\mathrm{Fe}(\mathrm{III})$-grafted $\mathrm{TiO}_{2}$ photocatalyst, J. Phys. Chem. C 114 (2010) 16481-16487.

[9] C.C. Weng, K.H. Wei, Selective distribution of surface-modified $\mathrm{TiO}_{2}$ nanoparticles in polystyrene-b-poly(methyl methacrylate) diblock copolymer, Chem. Mater. 15 (2003) 2936-2941.

[10] J.C. Yu, W. HO, J. Lin, H. Yip, P.K. Wong, Photocatalytic activity, antibacterial effect, and photoinduced hydrophilicity of $\mathrm{TiO}_{2}$ films coated on a stainless steel substrate, Environ. Sci. Technol. 37 (2003) 2296-2301.
[11] X.W. Zhang, M.H. Zhou, L.C. Lei, Co-deposition of photocatalytic Fe doped $\mathrm{TiO}_{2}$ coating by MOCVD, Catal. Commun. 7 (2006) 427-431.

[12] R.S. Sonawane, B.B. Kale, M.K. Dongare, Preparation and photo-catalytic activity of $\mathrm{Fe}-\mathrm{TiO}_{2}$ thin films prepared by sol-gel dip coating, Mater. Chem. Phys. 85 (2004) 52-57.

[13] H. Xu, R.Y. Jiao, F. Xiao, D.S. Wang, Relative importance of hydrolyzed Al species $\left(\mathrm{Al}_{\mathrm{a}}, \mathrm{Al}_{\mathrm{b}}, \mathrm{Al}_{\mathrm{c}}\right)$ on residual $\mathrm{Al}$ and effects of nano-particles (Fe-surface modified $\mathrm{TiO}_{2}$ and $\mathrm{Al}_{2} \mathrm{O}_{3}$ ) on coagulation process, Colloids Surf. A 446 (2014) 139-150.

[14] H. Xu, W. Jiang, F. Xiao, D.S. Wang, The characteristics of flocs and zeta potential in nano- $\mathrm{TiO}_{2}$ system under different coagulation conditions, Colloids Surf. A 452 (2014) 181-188

[15] H. Xu, R.Y. Jiao, F. Xiao, D.S. Wang, Effects of different coagulants in treatment of $\mathrm{TiO}_{2}$-humic acid (HA) water and the aggregate characterization in different coagulation conditions, Colloids Surf. A 446 (2014) 213-223.

[16] P. Jarvis, B. Jefferson, S.A. Parsons, How the natural organic matter to coagulant ratio impacts on floc structural properties, Environ. Sci. Technol. 39 (2005) 8919-8924.

[17] T. Li, Z. Zhu, D.S. Wang, C.H. Yao, H.X. Tang, The strength and fractal dimension characteristics of alum-kaolin flocs, Int. J. Miner. Process 82 (2007) 23-29.

[18] F. Xiao, K.M. Lam, X.Y. Li, R.S. Zhong, X.H. Zhang, PIV characterisation of flocculation dynamics and floc structure in water treatment, Colloids Surf. A 379 (2011) 27-35.

[19] R.J. Fraccois, Strength of aluminum hydroxide flocs, Water Res. 21 (1987) 1023-1030.

[20] P. Jarvis, B. Jefferson, S.A. Parsons, How the natural organic matter to coagulant ratio impacts on floc structural properties, Envion. Sci. Technol. 39 (2005) 8919-8924.

[21] E.L. Sharp, P. Jarvis, S.A. Parsons, B. Jefferson, The impact of zeta potential on the physical properties of ferric-NOM floc, Environ. Sci. Technol. 40 (2006) 3934-3940.

[22] E.L. Sharp, P. Jarvis, S.A. Parsons, Floc structural characteristics using conventional coagulation for a high doc, low alkalinity surface water source, Water Res. 40 (2006) 2727-2737.

[23] J.C. Wei, B.Y. Gao, O.Y. Yue, Y. Wang, W.W. Li, X.B. Zhu, Comparison of coagulation behavior and floc structure characteristic of different polyferriccationic polymer dual-coagulants in humic acid solution, Water Res. 43 (2009) 724-732.

[24] J.L. Lin, C.J.M. Chin, C.P. Huang, J.R. Pan, D.S. Wang, Coagulation behavior of $\mathrm{Al}_{13}$ aggregates, Water Res. 42 (2008) 4281-4290.

[25] J. Bottero, D. Tchoubar, M. Axelos, P. Quienne, F. Fiessinger, Flocculation of silica colloids with hydroxy aluminum polycations. Relation between floc structure and aggregation mechanisms, Langmuir 6 (1990) 596-602.

[26] M.Q. Yan, D.S. Wang, J.R. Ni, J.H. Qu, C.W.K. Chow, H.L. Liu, Mechanism of natural organic matter removal by polyaluminum chloride: effect of coagulant particle size and hydrolysis kinetics, Water Res. 42 (2008) 3361-3370.

[27] A. Yadav, S. Mukherji, A. Garg, Removal of chemical oxygen demand and color from simulated textile wastewater using a combination of chemical/physicochemical processes, Ind. Eng. Chem. Res. 52 (2013) 10063-10071.

[28] X.Y. Li, C.W. Wang, Y. Qian, Y.J. Wang, L.W. Zhang, Simultaneous removal of chemical oxygen demand, turbidity and hardness from biologically treated citric acid wastewater by electrochemical oxidation for reuse, Sep. Purif. Technol. 107 (2013) 281-288. 